\title{
Latent inhibition in honeybees
}

\author{
CHARLES I. ABRAMSON and M. E. BITTERMAN \\ University of Hawaii, Honolulu, Hawaii
}

\begin{abstract}
Aversive conditioning was studied in individual honeybees flying back and forth between the hive and the sill of an open laboratory window, where they took sucrose solution from a target so constructed that shock could be delivered while the proboscis was in contact with the solution. During feeding, a conditioned stimulus-substrate vibration or airstream-was paired with brief shock avoidable by interruption of feeding. In Experiment 1, unreinforced preexposure of the conditioned stimulus was found to retard acquisition (latent inhibition). In Experiment 2, which was designed to inquire into the stimulus specificity of the effect, differential conditioning was found to be impaired by unreinforced preexposure of the positive stimulus and facilitated by unrein forced preexposure of the negative stimulus. In Experiment 3, a summation experiment designed to test various alternative explanations of the effect, a preexposed stimulus was found to suppress response to an excitatory conditioned stimulus when the two stimuli were presented together.
\end{abstract}

Explorations of learning in honeybees under conditions analogous to those used for the study of learning in vertebrates show a wide range of similarities that we find surprising in view of the remoteness of common ancestry and the vast differences in neural organization (Abramson, 1986; Bitterman, Menzel, Fietz, \& Schäfer, 1983; Couvillon \& Bitterman, 1980, 1982, 1984; Couvillon, Klosterhalfen, \& Bitterman, 1983; Menzel \& Bitterman, 1983; Sigurdson, 1981a, 1981b). While the underlying mechanisms may in some cases be homologous, it is perhaps to be suspected that others have evolved independently in the face of similar adaptive pressures (Bitterman, 1975). Convergence is indicated by the discovery in honeybees of successive negative incentive contrast (Couvillon \& Bitterman, 1984), a phenomenon well known in rats which has failed repeatedly to appear in descendants of certain older vertebrate lines (see Flaherty, 1982; for work subsequent to that reviewed by Flaherty, see Schmajuk, Segura, \& Ruidiaz, 1981, and Couvillon \& Bitterman, 1985). Another such phenomenon may be latent inhibition (retardation of excitatory conditioning by unreinforced preexposure of the conditioned stimulus), which has been found in a variety of mammals (Lubow, 1973) but has not yet been clearly demonstrated in nonmammalian vertebrates (Shishimi, 1985). In the experiments reported here, we show latent inhibition in honeybees and begin to examine its functional relation to latent inhibition in mammals.

\section{EXPERIMENT 1}

We came upon latent inhibition in the course of work on aversive conditioning in individual honeybees visting

This work was supported by Grant BNS 83-1705I from the National Science Foundation. Requests for reprints should be addressed to M. E. Bitterman, Békésy Laboratory of Neurobiology, 1993 East-West Road, Honolulu, HI 96822. the laboratory regularly for food (Abramson, 1986). During the feeding, which could be counted on to last at least $1 \mathrm{~min}$, a conditioned stimulus (CS) was paired with a brief pulse of shock (the unconditioned stimulus, or US). The shock could be avoided simply by withdrawal of the proboscis from the food, although the typical response to the CS (after conditioning), as to the US (when it was not avoided), was flying up from the target for a few seconds. When preliminary observations suggested that unreinforced preexposure to the CS retarded conditioning, we attempted a formal demonstration of the phenomenon.

\section{Method}

Subjects. The subjects were 32 experimentally naive honeybees (Apis mellifera) from our own hives situated in the immediate vicinity of the laboratory. They were selected at random from a group of foragers at a feeding station providing $10 \%-15 \%$ sucrose solution. A single animal was picked up in a small matchbox and carried to a target containing $50 \%$ sucrose set on the sill of an open laboratory window. While the animal was feeding, it was marked with a spot of colored lacquer, and after it finished feeding it was free to leave for the hive. Typically, the bee returned to the target within a few minutes, but if not, it was recaptured at the feeding station (where it usually could be found) and placed again on the target. The pretraining ended with the subject's first return to the laboratory of its own accord, after which it could be counted on to shuttle regularly between the hive and the laboratory.

Apparatus. The target used in this experiment was made of a petri dish, $5.5 \mathrm{~cm}$ in diameter, with a conductive copper plate $(5 \mathrm{~cm}$ in diameter) mounted on its cover. In the center of the target was an insulated feeding hole $(1 \mathrm{~cm}$ in diameter and $.5 \mathrm{~cm}$ deep $)$ that was filled with $50 \%$ sucrose solution. When the animal was standing on the copper plate and its proboscis was in contact with the solution, a pulse of shock ( $25 \mathrm{~V}$ ac, $35 \mathrm{msec}$ in duration) could be delivered (the plate being connected to one side of the supply and the cup to the other). To generate the CS, which was substrate vibration, the target was mounted on a vibrator (Goodman Industries, Wembly, England) set to produce a frequency of $50 \mathrm{HZ}$ and a peak-to-peak amplitude of .15 mm.

Procedure. The subjects were assigned in quasi-random fashion to two groups of 16 each, Group $\mathrm{A}-/ \mathrm{A}+$ and Group $0 / \mathrm{A}+$. In the first stage of the experiment, which consisted of 10 visits, the animals of Group A-/A+ had $105-\mathrm{sec}$ exposures to the vibratory stimu- 
lus (A). The stimulus was presented once on each visit, either 5 or $30 \mathrm{sec}$ after the beginning of feeding (in balanced order). The animals of Group $0 / \mathrm{A}+$ were unstimulated $(0)$. In the second stage of the experiment, which also consisted of 10 visits, paired presentations of vibration and shock (CS-US interval $=5 \mathrm{sec}$ ) were scheduled in the same way for both groups, one per visit, after either 5 or $30 \mathrm{sec}$ of feeding. In both stages of the experiment, interruption of feeding in response to the CS (flying up from the target) was recorded.

\section{Results}

In Figure 1, the results of the experiment are plotted in terms of the proportion of animals responding to the $\mathrm{CS}$ on each visit. The performance of Group $\mathrm{A}-/ \mathrm{A}+$ in the first stage of the experiment shows some tendency to respond to the CS in advance of the first reinforcement11 of the 16 animals made a total of 17 responses - as well as some tendency for the response to habituate in the course of repeated stimulation. In the second stage of the experiment, the $\mathrm{A}-/ \mathrm{A}+$ animals performed more poorly than the $0 / \mathrm{A}+$ animals, which conditioned rapidly. Analysis of variance based on the number of avoidance responses by each subject in each block of five visits shows significant effects of groups $[F(1,30)=35.66$, $p<.0001]$ and of blocks $[F(1,30)=39.06, p<.0001]$, as well as a significant groups $\times$ blocks interaction $[F(1,30)=4.30, p=.0467]$. It should be noted that the performance of Group 0/A+ in the second block of visits does not reflect the failure of some animals to conditionevery one of them did. A better explanation of the variability is to be found in the use of an avoidance contingency; as the frequency of responding to the CS increased, the frequency of shock declined.

\section{EXPERIMENT 2}

Our purpose in this experiment was to examine the stimulus specificity of latent inhibition in honeybees. Work on latent inhibition in sheep, goats, rats, and rabbits has, of course, shown considerable specificity (Carlton \& Vogel, 1967; Lubow \& Moore, 1959; Reiss \& Wagner, 1972; Siegel, 1969). The conventional design of such experiments is to condition a stimulus after unreinforced preexposure of either the same or another

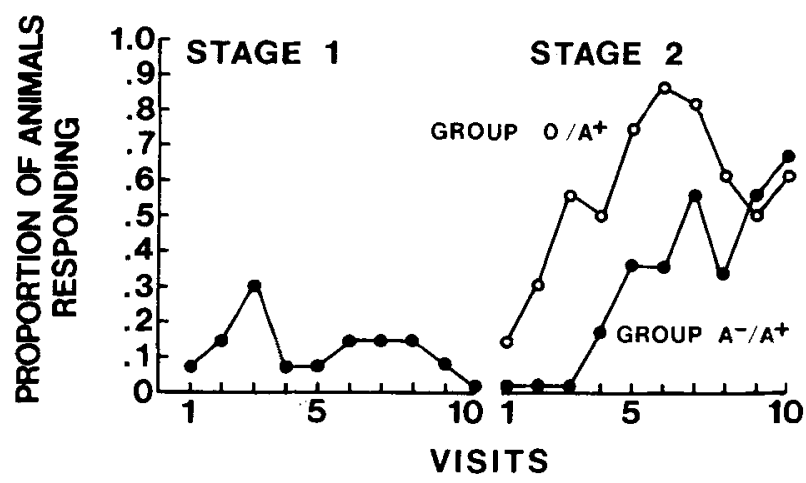

Figure 1. The proportion of animals in each group responding to the $C S$ on each visit in Experiment 1. stimulus, but here a different design was employed, on the assumption that it would prove to be more powerful: Three groups of honeybees were trained to discriminate between two stimuli-substrate vibration and airstreamafter unreinforced preexposure to the positive stimulus, the negative stimulus, or neither.

\section{Method}

Subjects. The subjects were 48 honeybees from our own hives; they were recruited and pretrained in the manner previously described.

Apparatus. The apparatus used in Experiment 1 was modified to provide another CS. For a diagram, see Abramson (1986). Mounted above the target at a height of $2.5 \mathrm{~cm}$ was a second petri dish of the same size. Drilled in the bottom of the second dish were 46 small holes through which a stream of compressed air (7.5 psi) could be directed upon the animal below. A solenoid-operated valve was used to turn the stream on and off.

Procedure. The subjects were assigned in quasi-random fashion to three groups of 16 each, Group $\mathrm{A}-/ \mathrm{A}+\mathrm{B}-$, Group $\mathrm{B}-/ \mathrm{A}+\mathrm{B}-$, and Group $0 / A+B-$. A and $B$ represent the two stimuli, whose roles were balanced fully; for half the animals in each group, $A$ was vibration and $B$ was airstream, whereas the opposite was true for the remaining animals in each group. In the first stage of the experiment, which consisted of 10 visits, the animals of Group $A-/ A+B-$ had 205 -sec exposures to A, two on each visit, one beginning after $5 \mathrm{sec}$ and the other after $30 \mathrm{sec}$ of feeding. The animals of Group $B-/ A+B-$ were exposed in the same way to $B$; the animals of Group $0 / A+B-$ were exposed to neither of the stimuli. In the second stage of the experiment, which consisted of 20 visits, the animals of all three groups were differentially conditioned. On half the visits, in balanced order, A was presented after $5 \mathrm{sec}$ of feeding and B after $30 \mathrm{sec}$; the sequence of stimuli was reversed on the remaining visits. The duration of each stimulus was $5 \mathrm{sec}$, with a pulse of shock ( $35 \mathrm{msec}, 25 \mathrm{~V} \mathrm{ac}$ ) scheduled at the termination of A but not B. Again, the shock was avoidable, affecting the animal only if its proboscis was in contact with the sucrose solution, and interruption of feeding in response to each of the stimuli was recorded.

\section{Results}

In the first stage of the present experiment, as in the first stage of the previous one, there was some small amount of responding to the preexposed stimuli. Five of the 16 animals exposed to vibration made a total of 11 responses, and the results for the 16 animals exposed to airstream were exactly the same; 5 of the animals in Group $A-/ A+B-$ made a total of 14 responses, and the same number of animals in Group B-/A+B- made a total of 8 responses. The performance of each of the three groups in the second stage of the experiment is plotted in Figure 2 in terms of the proportion of animals responding to each of the two stimuli on each visit. The evidence of stimulus specificity is clear: At the outset of the second stage, there was little tendency to respond to the preexposed stimulus, which retarded differential conditioning in Group $\mathrm{A}-/ \mathrm{A}+\mathrm{B}-$ relative to the performance of the unstimulated Group $0 / A+B-$, and facilitated it in Group B-/A+B-. Analysis of variance based on the number of avoidance responses by each subject to each stimulus in each block of five visits shows a significant effect of positive versus negative stimuli $[F(1,36)=$ $406.43, p<.0001]$ and a significant interaction of stimuli 


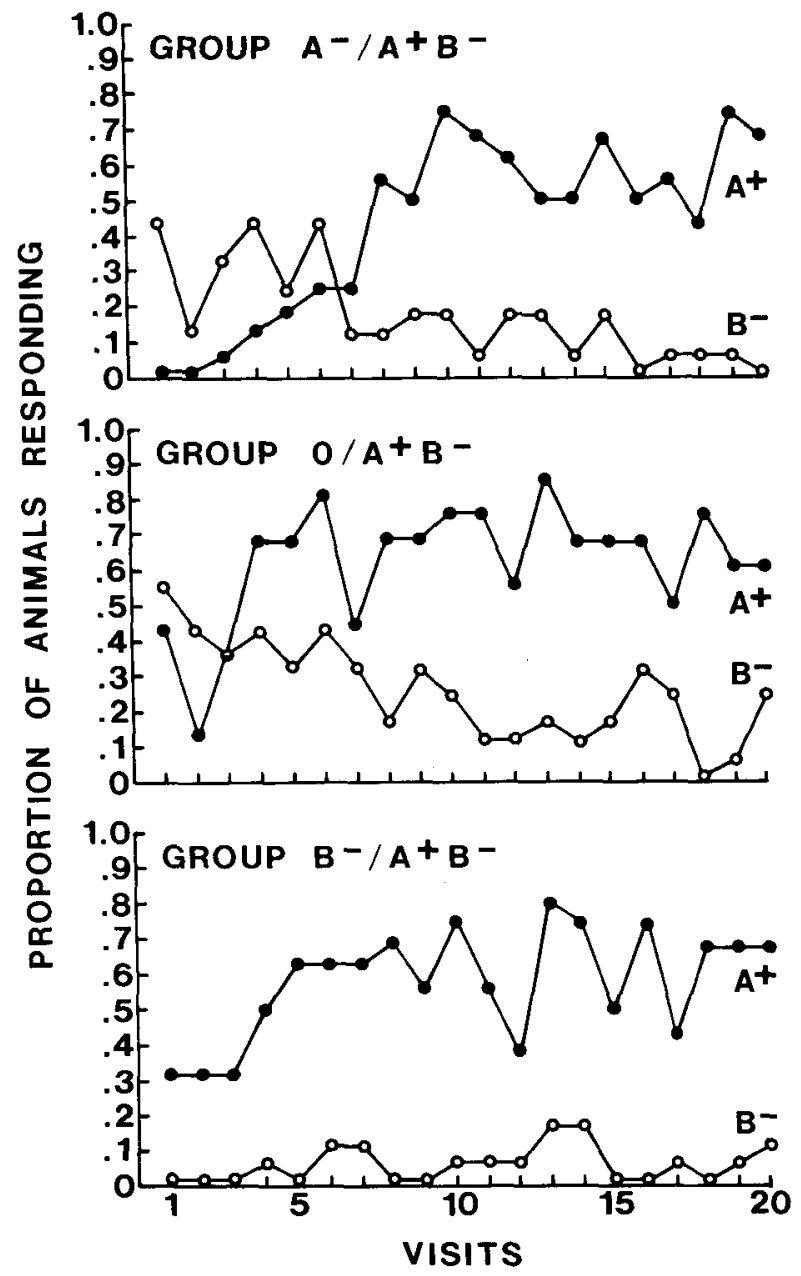

Figure 2. The proportion of animals in each group responding to each of the two stimuli on each visit in the second stage of Experiment 2.

$\times$ blocks $[F(3,108)=54.07, p<.0001]$. It also shows a significant interaction of groups $\times$ stimuli $[F(2,36)=$ $16.90, p<.0001]$ and of groups $\times$ stimuli $\times$ blocks $[F(6,108)=8.63, p<.0001]$. Response to $\mathrm{A}+$ was significantly greater in Group $0 / A+B-$ than in Group $\mathrm{A}-/ \mathrm{A}+\mathrm{B}-[F(1,30)$ for groups $=27.75$, $p<.0001 ; F(3,90)$ for the interaction of groups $\times$ blocks $=4.34, p=.0001]$, and response to $\mathrm{B}-$ was significantly greater in Group 0/A+B- than in Group B-/A+B$[F(1,30)$ for groups $=44.03, p<.0001 ; F(3,90)$ for the interaction of groups $\times$ blocks $=12.19, p<.0001]$.

\section{EXPERIMENT 3}

Having demonstrated latent inhibition in Experiment 1, and having replicated the effect and demonstrated its stimulus specificity in Experiment 2, we began in a third experiment to try to understand what produces it. There is a general consensus in the vertebrate literature that latent inhibition cannot be understood in terms of inhibition (Pavlov, 1927) or in terms of competing responses established during preexposure (Lubow \& Moore, 1959), despite an experiment by Kremer (1972) in which a preexposed stimulus was found to reduce response to a conditioned excitor when presented with it. The results of other summation tests and of attempts with differential reinforcement to establish preexposed stimuli as conditioned inhibitors (Baker \& Mackintosh, 1977; Halgren, 1974; Reiss \& Wagner, 1972; Rescorla, 1971; Solomon, Brennan, \& Moore, 1974) have suggested instead a loss of salience or associability, although there is little agreement as to how that happens (Lubow, Weiner, \& Schnur, 1981; Mackintosh, 1983; Pearce \& Hall, 1980; Whitlow \& Wagner, 1984). In the present experiment, the summation strategy was used again in an effort to determine why unreinforced preexposure retards avoidance conditioning in honeybees. The simplest of the several hypotheses considered was that the stimulus tends originally to evoke the avoidance response in some degree, and that this tendency, which supports conditioning in the naive animal, is diminished by preexposure (habituation). A second hypothesis was that preexposure reduces attention to the stimulus and therefore interferes with conditioning (salience decrement). A third hypothesis was that the preexposed stimulus acquires inhibitory or other properties which tend actively to oppose avoidance conditioning (suppression).

The design of the experiment called for three groups of animals. The first group $(\mathrm{A}-/ \mathrm{B}+/ \mathrm{AB}-)$ was preexposed to stimulus $\mathrm{A}$, conditioned to stimulus $\mathrm{B}$, and then given unreinforced tests with $A$ and $B$ presented simultaneously. The second group $(\mathrm{A}-/ \mathrm{B}+/ \mathrm{B}-)$ was treated in the same way as the first, except that the tests were with $\mathrm{B}$ alone. A third group $(0 / \mathrm{B}+/ \mathrm{AB}-)$ was treated in the same way as the first, except that there was no preexposure to $\mathrm{A}$. The habituation hypothesis suggested that there would be less response to $A B$ in Group $A-/ B+/ A B-$ than in Group $0 / B+/ A B-$, but not less than in Group A-/B+/B-. The salience-decrement hypothesis prepared us for the possibility that there would be more response to $A B$ in Group $A-/ B+/ A B-$ than in Group $0 / B+/ A B-$, on the assumption that the less salient A would produce a smaller generalization decrement; to the extent that generalization decrement is important, there should be less response in Group $0 / B+/ A B-$ than in Group $A-/ B+/ B-$, since the effects of preexposure were found in Experiment 2 to be stimulus specific. The suppression hypothesis suggested that there would be less response in Group $\mathrm{A}-/ \mathrm{B}+/ \mathrm{AB}-$ than in either of the other groups.

\section{Method}

Subjects. The subjects were 36 honeybees from our own hives, recruited and pretrained as in the previous experiments.

Apparatus. The apparatus was the same as in Experiment 2.

Procedure. Again the stimuli were vibration and airstream, each $5 \mathrm{sec}$ in duration, and again their roles in the experiment were fully balanced. Half the animals in Group $A-/ B+/ A B-$ and half the animals in Group $\mathrm{A}-/ \mathrm{B}+/ \mathrm{B}-$ were preexposed to vibration in the first stage of the experiment and conditioned to airstream in the 
second; the rest were preexposed to airstream and conditioned to vibration; half the animals in Group $0 / \mathrm{B}+/ \mathrm{AB}-$ were conditioned to vibration and the rest to airstream. There were 10 visits in the first stage of the experiment, on each of which, for Groups $\mathrm{A}-/ \mathrm{B}+/ \mathrm{AB}-$ and $\mathrm{A}-/ \mathrm{B}+/ \mathrm{B}-$, stimulus $\mathrm{A}$ was exposed after either 5 or $30 \mathrm{sec}$ of feeding (the earlier exposure on 5 visits and the later exposure on the rest, in balanced order). For Group $0 / B+/ A B-$, there were no preexposures in the first stage. In the second stage of the experiment, which consisted of 5 visits, there was a conditioning trial with $B$ on each visit for all three groups; a pulse of avoidable shock ( $35 \mathrm{msec}, 25 \mathrm{~V} \mathrm{ac}$ ) was scheduled at the termination of $B$. Two of the five trials were given early in the feeding period (after $5 \mathrm{sec}$ ) and three later on (after $30 \mathrm{sec}$ ). In the third stage of the experiment, which consisted of 10 visits, Groups $A-/ B+/ A B-$ and $0 / B+/ A B-$ were tested with the compound (unreinforced), and Group $A-/ B+/ B-$ was tested with $B$ alone (unreinforced). There was one test on each visit, which came after either $5 \mathrm{sec}$ or $30 \mathrm{sec}$ of feeding, in balanced order. Interruptions of feeding in response to the stimuli were recorded throughout.

\section{Results}

Again, in the first stage of the experiment there was some small amount of responding to the preexposed stimuli. Of the 12 subjects exposed to vibration in the first stage, 6 made a total of 7 responses; of the 12 subjects exposed to airstream, 6 made a total of 9 responses; of the animals in Group $A-/ B+/ A B-, 7$ made a total of 10 responses; of the animals in Group $A-/ B+/ B-, 5$ made a total of 6 responses. In the second stage of the experiment, all three groups conditioned rapidly and at the same rate, as shown in Figure 3, where their performance is plotted in terms of the proportion of animals responding to $\mathrm{B}$ on each visit. Analysis of variance based on the number of avoidance responses by each subject on the five visits yields an insignificant effect of groups $[F(2,33)=1.51, p=.2348]$. The performance of the three groups in the third stage of the experiment also is plotted in Figure 3, and here there was a clear difference in level of responding-less responding in Group $A-/ B+/ A B$ - than in either of the others-which analysis of variance shows to be significant $[F(2,33)$ for groups $=10.56, p=.0003 ; F(2,33)$ for the interaction of groups $\times$ five-visit blocks $=3.91, p=.0299]$. Group $A-/ B+/ A B$ - differs significantly from Group $\mathrm{A}-/ \mathrm{B}+/ \mathrm{B}-[F(1,22)$ for groups $=9.73, p=$

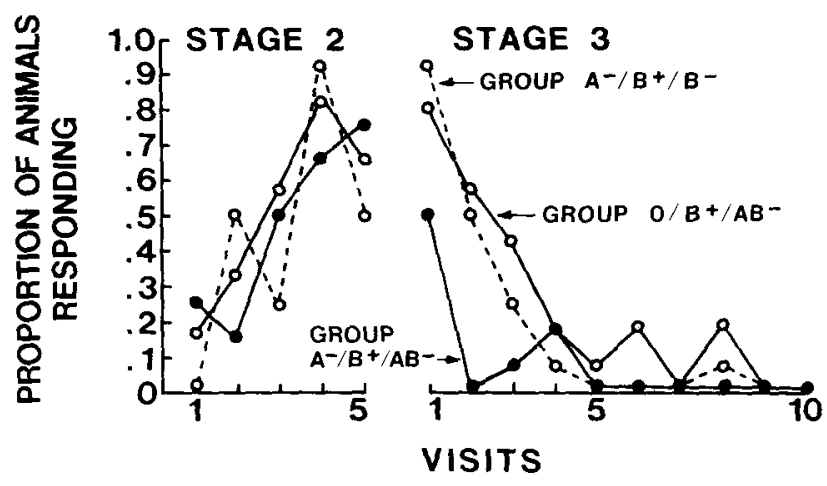

Figure 3. The proportion of animals in each group responding on each visit in the second and third stages of Experiment 3.
$.0050 ; F(1,22)$ for the groups $\times$ blocks interaction $=$ $5.86, p=.0242]$ and also from Group $0 / \mathrm{B}+/ \mathrm{AB}-$ $[F(1,22)$ for groups $=24.18, p=.0001 ; F(1,22)$ for the groups $\times$ blocks interaction $=8.00, p=.0098]$, but Groups $A-/ B+/ B-$ and $0 / B+/ A B-$ do not differ significantly from each other $[F(1,22)$ for groups $=1.98$, $p=.1724 ; F<1$ for the groups $\times$ blocks interaction].

From the fact that Group $A-/ B+/ A B-$ responded less in the test than Group $A-/ B+/ B-$, we conclude that the preexposed stimulus continued to be effective, and that its effect was to suppress responding. An interpretation of the difference in terms of generalization decrement is ruled out by the fact that Group $A-/ B+/ A B-$ also responded less than did Group $0 / B+/ A B-$, whose performance did not differ significantly from that of Group $A-B+/ B-$. Clearly, the suppressing effect of $A$ on response to $B$ evident in the performance of Group $A-/ B+/ A B-$ was produced by unreinforced preexposure.

\section{DISCUSSION}

At the outset of these experiments, there was some reason to doubt that latent inhibition would be found in honeybees, because a previous experiment on proboscisextension conditioning with sucrose as the US had failed to show a retarding effect of preexposure (Bitterman et al., 1983). Further effort should be made to find latent inhibition in proboscis-extension conditioning on the assumption that the present results actually do reflect some general honeybee process rather than a process specific to the procedure employed.

While the results of Experiment 3 support the suppression hypothesis, the mechanism of suppression remains to be determined. The possibility suggested by traditional Pavlovian theory is that the preexposed stimulus acquires inhibitory properties-that what we see in the third stage of Experiment 3 is the summation of excitation and inhibition previously inferred from responses to compounds of stimuli positively and negatively correlated with food (Couvillon \& Bitterman, 1980). This explanation contradicts the prevailing assumption in the contemporary vertebrate literature that the source of inhibition is not nonreinforcement per se but negative correlation with reinforcement, an assumption supported by the work on proboscis-extension conditioning in honeybees (Bitterman et al., 1983).

An alternative explanation of the present results was suggested by R. F. Westbrook (personal communication, May 1985) and, later, by several other colleagues: Because preexposure occurred in our experiments while the animals were feeding, the preexposed stimulus may have acquired appetitive properties that interfered with its subsequent aversive conditioning or that attenuated expression of the aversive properties of a stimulus presented with it (Konorski \& Szwejkowska, 1952). In the widely cited work of Rescorla (1971) that gave different results for rats, preexposure and subsequent aversive conditioning also took place in an appetitive context, but our circum- 
stances may have been more favorable for the appetitive conditioning at least of contextual stimuli, because the food was available constantly, rather than on an interval schedule. There is, in fact, some indication of slower aversive conditioning in our unpreexposed animals than in those trained by Abramson (1986), which had fewer prior visits and correspondingly less opportunity for contextual conditioning (Couvillon \& Bitterman, 1980). Although the preexposed stimulus is not itself a good predictor of food, the appetitive properties ascribed to it may derive from association with contextual stimuli (see Couvillon \& Bitterman, 1982, for evidence of within-compound association in honeybees). It should be noted, however, that experiments with vertebrates have not consistently shown a retarding effect of appetitive conditioning on subsequent aversive conditioning (Dickinson \& Pearce, 1977), but, on occasion, have shown quite the opposite effect (e.g., Scavio \& Gormezano, 1980). A somewhat different interpretation of the present results, worth considering, is that the original tendency of the preexposed stimulus to evoke the flight response contemplated in the habituation hypothesis is not simply habituated but is counterconditioned in the feeding context-that is, persistence in feeding is learned. Whereas the traditional Pavlovian interpretation suggests that we should be able to find latent inhibition in proboscis-extension conditioning (which is purely appetitive), the alternative interpretations (which rely on appetitive-aversive competition) help to explain why we might not.

Before anything can be said about the relation between the mechanisms of latent inhibition in honeybees and vertebrates, more work will have to be done, not only with honeybees, but also with vertebrates. A first order of business might be to try to understand why similar techniques should yield such different results as those of Rescorla (1971) and Kremer (1972). Kremer's results, which point to inhibition or response-competition, rather than to loss of salience or associability, might simply be dismissed as anomalous in view of the agreement of a variety of independent investigators with Rescorla, but the contradictory results are not, for the most part, persuasive; although they do not go in Kremer's direction, neither do they go very clearly in the other direction. It is conceivable that there are opposed processes at work in these experiments--according to Hall, Kaye, and Pearce (1985), for example, a preexposed stimulus may lose associability as it acquires inhibitory properties-and that new experimental designs will be required to distingish them properly.

\section{REFERENCES}

Abramson, C. I. (1986). Aversive conditioning in honeybees (Apis mellifera). Journal of Comparative Psychology, 100, 108-116.

BAKER, A. G., \& MACKINTOSH, N. J. (1977). Excitatory and inhibitory conditioning following uncorrelated presentations of CS and UCS. Animal Learning \& Behavior, 5, 315-319.
Bitterman, M. E. (1975). The comparative analysis of learning. Science, 188, 699-709.

Bitterman, M. E., Menzel, R., Fietz, A., \& Schäfer, S. (1983). Classical conditioning of proboscis extension in honeybees (Apis mellifera). Journal of Comparative Psychology, 97, 107-119.

CARLTON, P. L., \& VOGEL, J. R. (1967). Habituation and conditioning. Journal of Comparative \& Physiological Psychology, 63, 348-351.

Couvillon, P. A., \& Bitterman, M. E. (1980). Some phenomena of associative learning in honeybees. Joumal of Comparative \& Physiological Psychology, 94, 878-885.

Couvillon, P. A., \& Bitterman, M. E. (1982). Compound conditioning in honeybees. Journal of Comparative \& Physiological Psychology, 96, 192-199.

Couvillon, P. A., \& Bitterman, M. E. (1984). The overlearning extinction effect and successive negative contrast in honeybees (Apis mellifera). Journal of Comparative Psychology, 98, 100-109.

Couvillon, P. A., \& Bitterman, M. E. (1985). Effect of experience with a preferred food on consummatory responding for a less preferred food in goldfish. Animal Learning \& Behavior, 13, 433-438.

Colvillon, P. A., Klosterhalfen, S \& Bitterman, M. E. (1983). Analysis of overshadowing in honeybees. Journal of Comparative Psychology, 97, 154-166.

Dickinson, A., \& PEARCE, J. M. (1977). Inhibitory interactions between appetitive and aversive stimuli. Psychological Bulletin, 84, 690-711

FlaherTy, C. F. (1982). Incentive contrast: A review of behavioral changes following shifts in reward. Animal Learning \& Behavior, 10, 409-440.

HaLgReN, C. R. (1974). Latent inhibition in rats: Associative or nonassociative? Journal of Comparative \& Physiological Psychology, 86 , 74-78.

Hall, G, Kaye, H., \& Pearce, J. M. (1985). Attention and conditioned inhibition. In R. R. Miller \& N. E. Spear (Eds.), Information processing in animals: Conditioned inhibition (pp. 185-207). Hillsdale, NJ: Erlbaum.

KonORSKI, J., \& SzWEJKowsKa, G. (1952). Chronic extinction and restoration of conditioned reflexes: IV. The dependence of the course of extinction and restoration of conditioned reflexes on the "history" of the conditioned stimulus (the principle of the primacy of first training). Acta Biologica Experimentalis, 16, 95-113

Kremer, E F. (1972). Properties of a preexposed stimulus. Psycho nomic Science, 27, 45-47.

LuBow, R E. (1973). Latent inhibition. Psychological Bulletin, 79. 398-407.

Lubow, R. E., Moore, A. U. (1959). Latent inhibition: The effect of nonreinforced pre-exposure to the conditional stimulus. Journal of Comparative \& Physiological Psychology, 62, 415-419.

Lubow, R. E., Weiner, I., \& SChNur, P. (1981). Conditioned attention theory. In G. H. Bower (Ed.), The psychology of learning and motivation (Vol. 15, pp. 1-49). New York: Academic Press.

Mackintosh, N. J. (1983). Conditioning and associative learning. New York: Oxford University Press.

MENZEL, R., \& BitTeRMAN, M. E. (1983). Learning by honeybees in an unnatural situation. In F. Huber \& H. Markl (Eds.), Neuroethology and behavioral physiology (pp. 206-215). Berlin, Heidelberg: Springer-Verlag.

Pavlov, I. P. (1927), Conditioned reflexes (G. V. Anrep, trans.). London: Oxford University Press.

Pearce, J. M., \& Hall, G. (1980). A model for Pavlovian learning: Variations in the effectiveness of conditioned but not of unconditioned stimuli. Psychological Review, 87, 532-552.

REISS, S., \& WAGNER, A. R. (1972). CS habituation produces a "Iatent inhibition effect" but no active "conditioned inhibition." Learning \& Motivation, 3, 237-245.

RESCORLA, R. A. (1971). Summation and retardation tests of latent inhibition. Journal of Comparative \& Physiological Psychology, 75, 77-81.

SCAVIO, M. J., \& Gormezano, I. (1980). Classical-classical transfer: 
Effects of prior appetitive conditioning upon aversive conditioning in rabbits. Animal Learning \& Behavior, 8, 218-224.

Schmajuk, N. A., Segura, E. T., \& Ruidiaz, A. C. (1981). Reward downshift in the toad. Behavioral \& Neural Biology, 33, 519-523.

SHISHImI, A. (1985). Latent inhibition experiments with goldfish (Carassius auratus). Journal of Comparative Psychology, 99, 316-327.

SiEgEL, S. (1969). Generalization of latent inhibition. Journal of Comparative \& Physiological Psychology, 69, 157-159.

Sigurdson, J. E. (1981a). Automated discrete-trials techniques of appetitive conditioning in honey bees. Behavior Research Methods \& Instrumentation, 13, 1-10.

SiguRDSON, J. E. (1981b). Measurement of consummatory behavior in honey bees. Behavior Research Methods \& Instrumentation, 13, 308-310.

Solomon, P. R., Brennan, G., \& Moore, J. W. (1974). Latent inhibition of the rabbit's nictitating membrane response as a function of CS intensity. Bulletin of the Psychonomic Society, 4, 445-448.

Whitlow, J W., JR., \& WAGNeR, A. R. (1984). Memory and habituation In H. V. S. Peeke \& L. Petrinovich (Eds.), Habituation, sensitization, and behavior (pp. 103-153). New York: Academic Press.

(Manuscript received August 14, 1985; revision accepted for publication January 27, 1986.) 